\title{
Commons Praxis: Towards a Critical Political Economy of the Digital Commons
}

\author{
Benjamin J Birkinbine
}

\author{
University of Nevada, Reno, USA, bbirkinbine@unr.edu
}

\begin{abstract}
The concept of the commons has provided a useful framework for understanding a wide range of resources and cultural activities associated with the creation of value outside of the traditional market mechanisms under capitalism (i.e. private property, rational selfinterest, and profit maximization). However, these communities often continue to intersect with capital and the state attempts to appropriate their resources. Recent scholarship has sought to unpack some of the contradictions inherent in the claims made about the revolutionary potential of the commons by offering conceptual frameworks for assessing commonsbased projects. This paper builds upon this research by developing a two-pronged argument. First, by drawing examples from the free software movement, I argue that critical political economy provides the most useful analytical framework for understanding the contradictions inherent in the relationship between capital and the commons. Second, I argue for a commons praxis that attempts to overcome some of these contradictions. Within this discussion, I build on the notion of 'boundary commoning' to understand organisational form, and I develop the concept of 'subversive commoning' for understanding various forms of commoning that seek to undermine the capitalist logics of the digital commons.
\end{abstract}

Keywords: Critical Political Economy, Commons, Commons-Based Peer Production, Free Software, Open Source

Acknowledgement: I would like to thank Christian Fuchs and Denise Rose Hansen at the Westminster Institute for Advanced Studies for their support during my time as part of the Critical Social and Digital Media Fellowship Programme. In addition, I would like to thank Ergin Bulut, Pasko Bilic, Sebastian Sevignani, Arwid Lund, and Mariano Zukerfeld, all of whom offered feedback on this project.

\section{Introduction}

In the search for alternatives to capitalism, the commons paradigm has emerged as a possible direction forward. The concept of the commons (Ostrom 1990; Thompson 1993; Linebaugh 2014; Hardt and Negri 2011; Bollier and Helfrich 2012; De Angelis 2017) has been used as a framework for informing and understanding the activities of various social movements that are actively working against the enclosure of public goods or commons-based resources. These range from natural resources like water, fish, grasslands, forests, or the atmosphere, to human-created resources like education, housing, or ideas and their expression. Whatever the resource, these movements are linked by their attempts to maintain or reinstitute community control over such resources, while resisting (to various degrees) state or corporate exploitation or control of the resource. The emergent ways that communities negotiate their relationship with either the state or capital has been the subject of scholarly interest and debate for at least the last 25 years. 
More recent scholarship has attempted to clarify some of the diverse ways in which the commons can be understood, particularly as an emancipatory practice in the face of the prevailing capitalist economy (Broumas 2017; De Angelis 2017; Dulong de Rosnay and Musiani 2016). De Angelis (2017), for example, has developed the notions of "commons value circuits" and "boundary commoning". These contributions provide a useful analytical framework for understanding how the commons and commons-based movements can be understood as alternative value systems and the ways they can intersect with capital circuits.

In this paper, I build on this scholarship by showing how such a framework can be applied specifically to the digital commons. By drawing examples from the free and open source software movement, I illustrate the dynamics that exist between capital and the commons value circuits, but I also argue that the power of these movements is still somewhat ambiguous, particularly considering the difficulty of preventing the digital commons from being used for unforeseen or unwanted purposes. To that end, I argue that communities involved in the creation and sustenance of the digital commons still need a progressive political project that goes beyond protecting commonsbased resources from enclosure - what I call the "politics of subsistence" - into actively seeking to integrate resources from the state and capital into commons circuits. To do this, I work from a critical political economic perspective that can most adequately account for the contradictions within the dialectic of capital and the commons. I suggest that the specific forms of progressive politics may vary, but such movements need to find strategies for building commons-based capacity. Movements informed by liberal-democratic theory will try to find ways to work within capital or the state to bring about a commons transition (P2P Foundation 2017), but this strategy remains somewhat limited (Broumas 2017). But a commons-based praxis informed by radical politics would seek to actively appropriate resources away from capital and the state into circuits of commons value. I call this strategy "subversive commoning".

To develop this argument in what follows, I begin with an explanation of the digital commons by focusing on free and open source software, which has been understood as a type of commons and commons-based peer production. Important for this discussion is the conceptual distinction between FLOSS products and processes. To develop framework further, I draw from some of the foundational literature for understanding the commons, most notably the work of Elinor Ostrom. I proceed to more recent scholarship that has attempted to reconcile commons-based movements and their limits within the contradictions of capitalism. Next, I provide greater detail about Massimo De Angelis's circuit of commons value and boundary commoning as key sites of struggle. Finally, by drawing examples from the free and open source software movement, I develop my argument for why we need to move beyond a politics of subsistence for the digital commons toward a progressive and multifaceted strategy for actively building commons-based communities as well as appropriating resources from capital and the state into commons value circuits.

\section{Free (Libre) and Open Source Software as Digital Commons}

Each year, The Linux Foundation releases a report titled, "Linux Kernel Development: How Fast it is Going, Who is Doing It, What They are Doing, and Who is Sponsoring the Work". The kernel is an essential part of an operating system that facilitates communication between computer hardware and software, and the Linux kernel development project is considered "one of the largest cooperative software projects ever attempted" (Corbet and Kroah-Hartman 2016, 1). Aside from a technical overview of how kernel development has changed over time, the authors also include 
information about the corporations that sponsor contributions to the kernel. For the latest version of the kernel, 221 companies contributed to its development, while 1,582 individual developers contributed. Table 1 provides an illustration of the top 15 most active companies that have sponsored contributions to the Linux kernel project. Other notable companies appearing outside the top 15 are Huawei Technologies, Facebook, Cisco, and Qualcomm.

$\begin{array}{lll}\text { Company } & \text { Changes } & \text { Percent } \\ \text { Intel } & 14,384 & 12.9 \% \\ \text { Red Hat } & 8,987 & 8.0 \% \\ \text { None } & 8,571 & 7.7 \% \\ \text { Unknown } & 7,582 & 6.8 \% \\ \text { Linaro } & 4,515 & 4.0 \% \\ \text { Samsung } & 4,338 & 3.9 \% \\ \text { SUSE } & 3,619 & 3.2 \% \\ \text { IBM } & 2,995 & 2.7 \% \\ \text { Consultants } & 2,938 & 2.6 \% \\ \text { Renesas Electronics } & 2,239 & 2.0 \% \\ \text { Google } & 2,203 & 2.0 \% \\ \text { AMD } & 2,100 & 1.9 \% \\ \text { Texas Instruments } & 1,917 & 1.7 \% \\ \text { ARM } & 1,617 & 1.4 \% \\ \text { Oracle } & 1,528 & 1.4 \%\end{array}$

Table 1: Contributors to Linux Kernel Development (Linux Foundation 2016, 12)

The Linux operating system is a form of Free (Libre) and Open Source Software, or FLOSS, which allows users to freely study, use, copy, modify, adapt, or distribute the software. FLOSS in general, and the Linux project specifically, have been hailed as the epitome of what is possible under commons-based peer production (Benkler 2006; Weber 2004; Moody 2001; Tapscott and Williams 2006). The commons and commons-based peer production, however, are often positioned in contradiction to capital and capitalist production (Marx 1976; Benkler 2006). This begs the question as to how and why major corporations would contribute directly to a FLOSS project, especially when that project seemingly does not directly contribute to corporate profits. The question becomes even more curious when one considers that many of the companies contributing to the kernel not only compete with one another in the market for information technology, but, like Microsoft and Google, are direct competitors with Linux in the market for operating systems. To understand why corporations are involved in FLOSS projects, we must first draw a conceptual distinction between FLOSS products as common-pool resources (Section 2.1) and the process of commons-based peer production that is used to create FLOSS products (Section 2.2).

\subsection{Commons Products: Common Pool Resources}

In tracing the roots of scholarship on the commons, most scholars bookmark the work of Elinor Ostrom (1990). The narrative often begins with Ostrom's work, and focuses on how her ideas developed and influenced subsequent generations of scholars. While Ostrom is a towering figure in scholarship on the commons, this simple narrative tends to obfuscate the broader history and context within which Ostrom's work is situated. Locher (2016) clarifies this history by demonstrating how Ostrom's work can be contextualised within a broader history of scholarly debates 
within economic, political, and anthropological scholarship concerned with the best way to achieve development. These debates were concerned with the role of the state, the market, and local communities in the project of development during the post-World War II period. This scholarship can be linked with the United States' international development projects through its flagship institution, USAID, in the 1970s80s.

Two assumptions in the approach to development dominated this period. One was the assumption of the "tragedy of the commons" or the fallacy of collective action, based primarily on the work of Garrett Hardin (1968). Hardin argued that the commons were ultimately unsustainable because they were at risk of overexploitation as members of the community acted in their self-interest to maximise personal gain. Thus, there was a fallacy in the logic of collective action; it was simply impossible for communities to govern collective resources without overexploiting them. The second assumption was that the liberal technocratic state ought to be the central agent in development through economic planning and coordinating large-scale development projects. This assumption was driven by the success of the New Deal and the welfare state in the post-war period. As such, the model was viewed as the primary means for developing countries in the Global South, where traditional practices would give way to modernisation to boost economic productivity.

During the 1970s, these assumptions were challenged by development anthropology, which analysed "adaptive socio-ecological strategies" used by local communities to ensure the survival of ecological resources (Locher 2016, 313). Often, these decision-making strategies were situated within complex systems of customs and social rules that developed from local communities' historical experiences with their broader environment. Challenges to these assumptions continued in the 1980 s as neoliberal economics emerged as an alternative to welfare state capitalism. Informed by rational choice theory, which privileged calculating and efficient economic decision-making by profit-maximising individuals, the goal was to unleash productive capacity in the private sector through deregulation and privatisation. Neoliberal doctrine thus argued for dismantling state regulation and withdrawing the state from social provision. As such, neoliberalism represented not just an economic doctrine but also "an ethic in itself, capable of acting as a guide for all human action, and substituting for all previously existing ethical beliefs" (Treanor 2005, n.p.).

Within this context, Ostrom's scholarship, in collaboration with others, sought to illuminate the ways that local communities govern common-pool resources outside of the binary of either state provision or market relations. The types of common-pool resources governed in this way vary, but the initial focus was on natural resources like fisheries, grazing pastures, groundwater basins, and irrigation systems. Later, Hess and Ostrom (2007) would expand the study of the commons to non-tangible resources like knowledge and information. What developed was a typology of common-pool resources that was organised along two axes: excludability and rivalry. Table 2 illustrates this typology. Excludability refers to the extent to which others can be prevented from using the resource. A resource with high excludability would be characterised as private property, since the owner would have the ability to exclude others from using the resource. Low excludability would describe a form of common property whereby many people can use the resource. Rivalry, on the other hand, refers to the extent to which one person's use of the resource detracts from another's ability to use the same resource. A resource with high rivalry would be a finite resource, while a resource with low rivalry could be used by many people without de- 
tracting from others' use of the resource. Intellectual property or a knowledge commons would be classified as a resource with low rivalry.

\begin{tabular}{|c|c|c|c|}
\hline & & \multicolumn{2}{|c|}{ Excludability } \\
\hline & & High & Low \\
\hline & High & $\begin{array}{l}\text { Individual Property } \\
\text { (finite resource) }\end{array}$ & $\begin{array}{l}\text { Common Property } \\
\text { (infrastructure) }\end{array}$ \\
\hline (ing & Low & $\begin{array}{l}\text { Intellectual Property } \\
\text { (books, music, consulting) }\end{array}$ & $\begin{array}{c}\text { Knowledge Commons } \\
\text { (language, knowledge, free } \\
\text { software) }\end{array}$ \\
\hline
\end{tabular}

Table 2: Typology of Property (adapted from Hess and Ostrom 2007; Frischmann 2012)

In this typology, FLOSS would be positioned as a knowledge commons because the resources produced by a community of contributors have low rivalry and low excludability. FLOSS products have low excludability because the code that is used to produce FLOSS products is often protected under alternative copyright licenses that enable widespread use of the code. These licenses are often referred to as 'copyleft' licenses, which are more permissible licenses than traditional copyright in the sense that they allow others to use, study, modify, adapt, or build upon the code if they provide attribution to the original author, and any product created using the code is also made available under similar licenses. ${ }^{1}$ FLOSS also constitutes a resource with low rivalry because one person's use of a digital product does not detract from another person's ability to do the same.

The value of this scholarship, then, was to provide a framework for understanding how communities can manage common resources outside of market relations or state provision. Rather than offering a prescriptive argument for how all communities ought to govern common resources, Ostrom's framework accounts for the diverse and varied ways that communities establish adaptable institutions of governance for managing complex problems. As such, Ostrom's project builds a 'bottom-up' approach for understanding community governance as well as the community's relationship to common-pool resources. Beyond the management of common-pool resources, however, we can also examine the ways that common-pool resources are produced and reproduced over time. To do so, we need to understand the processes involved in common-pool resource production.

\subsection{Commons Processes: Commons-Based Peer Production}

FLOSS in general, and the Linux project in particular, have been hailed as the epitome of what is possible under commons-based peer production (Benkler 2006; Weber 2004; Moody 2001; Tapscott and Williams 2006). Benkler argues commons-based peer production constitutes a new form of organisation that is "radically decentralized, collaborative, and nonproprietary; based on sharing resources and outputs among widely distributed, loosely connected individuals who cooperate with each other without relying on either market signals or managerial commands" $(2006,60)$. Benkler positions social production in general and peer production specifically in con-

1 There is a useful Wikipedia page with a table comparing some of the variations in software licenses, which can be found here https://en.wikipedia.org/wiki/Comparisonof free and open-source software licenses (last accessed June 17, 2017) 
tradiction to market-based production, arguing that these forms of production constitute a form of non-market production. While these spheres are not mutually exclusive, Benkler argues that diverse forms of non-market production, like FLOSS, have the capability to influence market production.

Peer production can challenge market-based production in at least a couple of ways. First, peer production can develop goods that will compete directly with those produced by commercial firms. In this case, commercial firms have a few different options: compete, do nothing, or adopt and adapt. If the firm competes, it will be required to create a better product than that offered by the nonmarket rival, although this may come at considerable cost to the firm. The firm may also do nothing to respond to peer production. This represents a risky strategy for the firm because the products created by peer production may gain additional market share, which provides a threat to the profitability of the commercial firm. Finally, and most importantly for the present study, the third option is to adapt to the changing forces in the market by adopting some of the strategies of the non-market forces. This type of strategic reorientation to non-market forces can have the consequence of altering the structure of an organisation. As Benkler notes,

As the companies that adopt this strategic reorientation become more integrated into the peer-production process itself, the boundary of the firm becomes more porous. Participation in the discussions and governance of open source development projects creates new ambiguity as to where, in relation to what is 'inside' and 'outside' of the firm boundary, the social process is $(2006,125)$.

For those firms that adopt this latter strategy, they arguably give up a certain level of control over the production process, which marks a dramatic change from previous production models. The traditional view of a firm's control over its informational resources or, more specifically, knowledge, is that knowledge can be viewed as an asset to be managed as an investment (Machlup 1962). However, the peer production process is arguably more innovative and efficient than centralised production processes (Von Hippel 2005). As a knowledge commons, FLOSS advocates encourage users to tinker, adapt, improve upon, or otherwise create something new. Proprietary and closed forms of production rely on strong intellectual property protection and the ability to exploit those property rights across a variety of platforms.

\subsection{Commons Products and Processes Summary}

The foregoing discussion clarified two conceptual distinctions in theorisations about the commons. On the one hand, we can understand the commons by analysing specific resources or goods held in common or produced in common by a community. On the other hand, the process used to create the commonwealth of FLOSS can be understood as a form of commons-based peer production, as it relies on inputs from a diffuse community of contributors. The argument presented predominantly by liberal-democratic theorists (Benkler 2006; Lessig 2005; Von Hippel 2005) has been to stress how these unique features can be beneficial both for the expansion of individual rights and democracy as well as for market growth. These arguments are valuable insofar as they highlight the possibilities of commons-based resources and peer production, but they are still limited by their failure to account for the structural limitations faced by those communities attempting to build alternative economic structures 
from within capitalism. That is, they fail to account for how the state and capital can still exercise power within commons-based communities.

\section{Toward a Critical Theory of the Digital Commons}

The unique characteristics of the digital commons - low excludability and low rivalry - enable digital resources to be shared by a large community with relative ease. At the same time, however, it is somewhat difficult to restrict unwanted use or appropriation of the resource. As such, the products of the digital commons potentially remain open for use by the state and capital to varying degrees depending on the licenses assigned to the resource. Bauwens and Kostakis (2014) refer to this relational contradiction as the "communism of capital", since large multinational corporations can subsume commons-based production within capital accumulation circuits, which limits the ability of commons-based movements to socially reproduce the commons over time. Furthermore, FLOSS products can also be used by the state to develop tools that assist in the expansion of surveillance capabilities, for example.

What is needed, then, is an account of the commons that incorporates a structural critique of capitalism. The goal of a critical political economy of the digital commons would be twofold. First, the project would illuminate the structural dynamics and power differentials that exist within commons-based communities, as well as the ways in which commons-based movements intersect with capital circuits. Second, the project would move beyond merely developing an analytical framework for understanding these power dynamics by developing a progressive political framework that could serve as a direction forward for a critical praxis of the digital commons. The analytical project of a critical political economy of the digital commons has benefited from two recent contributions: one from Antonios Broumas (2017), in which he develops a typology to differentiate between social democratic and critical theories of the commons; the second is Massimo De Angelis's development (2017) of an analytical framework for understanding commons value circuits.

\subsection{From Social Democratic Theories to Critical Theory}

Antonios Broumas (2017) developed a typology of commons theory to differentiate between social democratic and critical theories of the intellectual commons. His analysis may also be mapped onto the digital commons. According to Broumas, social democratic theories of the commons "employ political economic methodologies to analyse the dynamics that unfold between the commons, the market and the state with the aim to propose reconfigurations of these relations which will best serve social welfare" (Ibid., 103). Such theorists argue that by making progressive changes to existing structures, we can bring about a more just and egalitarian society. As it concerns the digital commons, the goal is to build repositories and platforms for commons-based knowledge and peer-to-peer production that can, in turn, bring about greater degrees of personal freedom as well as democratic decision-making (Bauwens 2005; Benkler 2006).

In the typology, as seen in Table 3 below, Broumas examined some of the foundational characteristics of each approach, focusing on epistemology, agency, structure, internal/external dynamics, normative criteria, and social change. Of particular interest in Table 3 is the relationship between the external dynamics, normative criteria, and social change sections. As for external dynamics, I have already discussed the ways that free software and the digital commons span both categories in certain ways. Mainly, the production occurring within free software communities can be subsumed within capital accumulation circuits, whether this is done with the willing coop- 
eration of the community or not. Two additional examples can illustrate these tendencies. The first is an instance of corporate sponsorship of a free software project. Red Hat, Inc., for example, is the largest and only publicly traded company whose business is founded purely on free software. The company sponsors the Fedora Project, which is a free software project. The company can incorporate contributions to the Fedora Project into its proprietary software, known as Red Hat Enterprise Linux, to sell to its clients (see Birkinbine 2017).

\begin{tabular}{|c|c|c|}
\hline & Social Democratic Theories & Critical Theories \\
\hline Epistemology & Political Economy & Critical Political Economy \\
\hline Agency & Social Individual(s) & Social Intellect \\
\hline Structure & Productive Community & Community of Struggle \\
\hline Internal Dynamics & Bottom-Up / Top-Down Emergence & $\mathrm{n} / \mathrm{a}$ \\
\hline External Dynamics & Co-Existence of Commons with Capital & $\begin{array}{l}\text { Commons / Capital Antagonism } \\
\text { and Sublation }\end{array}$ \\
\hline Normative Criteria & Deontological [reformist] & Deontological [subversive] \\
\hline Social Change & $\begin{array}{l}\text { The Commons as Substitute for the } \\
\text { Welfare State }\end{array}$ & $\begin{array}{l}\text { The Commons as Alternative to } \\
\text { Capitalism }\end{array}$ \\
\hline
\end{tabular}

Table 3: Social Democratic and Critical Theories of the Intellectual Commons (Broumas 2017, 121)

At the same time, Linux-based software like Red Hat also provides a second example of how free software production can be appropriated by the state. From the disclosures made by Edward Snowden about the United States' surveillance apparatus, we learned that Red Hat servers were used by the National Security Agency (NSA) to deploy XKEYSCORE, which was also Linux-based (Lee, Greenwald and MarquisBoire 2015). XKEYSORE's web interface effectively served as the NSA's search engine to conduct surveillance on a target of choice (see Lee, Greenwald and MarquisBoire 2015). These two examples demonstrate the tension that exists in the external dynamics of free software as digital commons and its ability to serve as a radical alternative to state and capital logics. The labour performed by free software contributors is still susceptible to exploitation by the state and capital even if it is undertaken with the intention of working against those forces. The analytical goal of a critical political economy would be the development of frameworks that can account for the ways that the commons can couple with capital accumulation circuits, and De Angelis (2017) has recently developed such a framework.

\subsection{Circuits of Commons Value}

By combining systems theory (Luhmann 1995), cybernetics (Maturana and Varela 1998) and Marxist-feminist political economy (Marx 1976; Dalla Costa and James 1975), De Angelis's task is to demonstrate how the commons can be understood as a system capable of bringing about a social revolution through ongoing iterations of commoning activity that are reproduced over time. Rather than arguing that such a revolution is imminent, however, he takes an epochal approach by focusing on how an emergent alternative value system like the commons have the potential to bring about a change in social relations. Just as capitalist social relations and subjectivities 
emerged in the feudal era, De Angelis views the commons as a similarly emergent value system responding to the excesses and exploitative tendencies of capitalism.

In the analytical portion of this work, De Angelis (2017) attempts to analyse the commons in the same way that Marx analysed capitalism. This leads him to develop a circuit of commons value, which accounts for the component parts of commons value systems. The circuit can be seen in Figure 1 below. In the circuit, an association of people $(A)$ claim collective ownership of their commonwealth $(\mathrm{CW})$, whether the sources of commonwealth are material, immaterial, commodity (C), or noncommodity (NC). This dual relationship between the association - as subjects - and their commonwealth - as objects - constitutes the commons (Cs). Then, through the activity of commoning $(\mathrm{cm})$, the commons are reproduced over time. Importantly, commoning should be understood as a process; not a state of being, but a state of becoming. Linebaugh (2008) explains that "commoning is embedded in a labor process"; it is collective, and it is "independent of the temporality of the law and the state" (Ibid., 45). As such, commoning includes the reproduction of both the objects that comprise the commons and subjectivities in which mutual aid, care, trust, and conviviality are reproduced over time. For De Angelis, this commons circuit can couple with capital circuits through the commodity form. His argument is not that these two can and ought to peacefully coexist, but that they do exist.

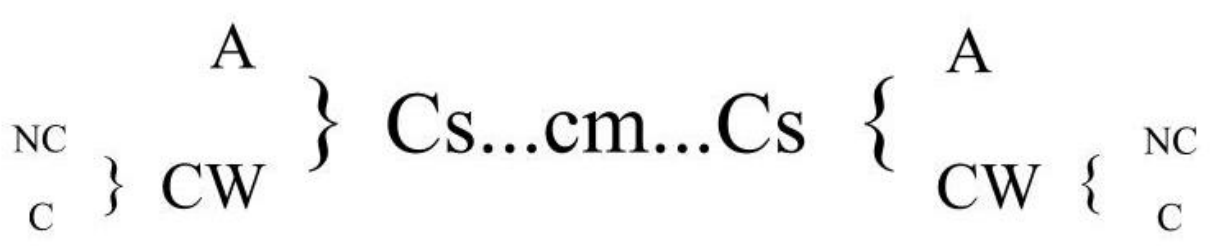

Figure 1. The Commons Circuit (De Angelis 2017, 193)

For example, when commoners must interact with the money form of capital, they do so only as a medium of exchange to gain access to the materials necessary to reproduce the commons and themselves over time. As this relates to the digital commons, a free software contributor or user still needs to have access to a computer to code the digital commons or to have access to them. In addition, the programmer will also need to have access to food, water, shelter, and all those things necessary to reproduce her own capacity to code the digital commons over time. These goods may be provided by the welfare state or one's family but, in the absence of such provision, one would need to intersect with capital circuit to obtain them. However, in De Angelis's formulation, the extent to which commoners engage with capital circuits is left up to the community and will vary depending on the specific needs of the community.

The coupling of commons circuits of value with capital accumulation circuits, whether willingly or out of necessity, still does not overcome many of the contradictions of the commons. De Angelis's formulation, then, seems to leave us with a picture of a "long social revolution", which would proceed primarily through the autonomous development of an emergent alternative value system from within capitalism. Such a value system would privilege commons value rather than capital accumulation. But there is another element in De Angelis's work that he draws from systems theory and cellular biology, which seems to contain the possibility of linking diverse commons movements. That is the concept of "boundary commoning", which is defined as 
the commoning that exists at the boundaries of the commons systems and that creates social forms of any scale, opens up the boundaries, establishes connections, and sustains commons ecologies, or that could reshape existing institutions from the ground up through commonalisation and create new ones. (De Angelis 2017, 24)

Boundary commoning has the potential to provide an organisational model for how diverse and distributed commons-based movements can work together toward a common goal. Through the multiplication of commoning activity and the interweaving of commons-based communities through boundary commoning, a commons movement could potentially lead to a tipping point at which social transformation is possible. In addition, De Angelis claims that commons movements could link with social movements to form a hybrid movement with the combined power to bring about social revolution. As he explains, these "are not movements of fragmented subjectivities sharing a particular passion, but movements of connected subjectivities whose connection is further increased by their social movement" (Ibid., 387). However, we are still left with the question of how to facilitate this type of commoning, as well as the persistent question of how to grow and sustain those movements that follow commons value circuits.

\subsection{Critical Theory and Digital Commons Summary}

Recent scholarship has attempted to parse some of the ontological and epistemological differences between varieties of scholarship on the commons. Broumas (2017), for example, differentiates between liberal-democratic and critical theories of the commons. Liberal-democratic theories tend to position the commons alongside market growth and the expansion of individual liberties, whereas critical theories understand the commons in an antagonistic relationship to capitalist logics and position commons movements as sites of social struggle. In addition, De Angelis (2017) developed the commons value circuit as an analytical device for understanding the alternative value system that undergirds commoning activity. While De Angelis takes an epochal view of a long social revolution that is emerging from within capitalism, commons-based movements are still confronted with the persistent problems of state and capital interference in their activities. In the following section, I outline some proposals for a commons praxis that would actively expand commoning capacity as well as the sources of their commonwealth.

\section{Commons Praxis: Moving the Commons Forward}

The task for a commons-based praxis is to overcome at least two hurdles. First is the task of determining an organisational form that would incorporate the lessons of critical scholarship on the commons. Critical scholarship has exposed some of the limitations of liberal-democratic or reformist approaches that seek to transition to a commons-based society from within existing institutions. While undoubtedly necessary to bring about change, we are still left with the limitation of radically transforming the organisation of society and social relations from within existing institutions, which are based on hierarchical organisational structures that tend to privilege political and economic elites with the requisite capital necessary to exercise influence by shaping policy agendas. These institutions cannot account for the multitude of distributed, 
diverse, and unique needs of local communities, and yet their existence will continue unless commons-based movements provide alternatives. This problem has become even more acute now that local publics can network with other communities of interest across national and international geographic boundaries. Second, a commons praxis needs to overcome the persistent problem of growing and sustaining commons-based movements over time. In this sense, a commons praxis needs to move beyond a politics of subsistence and institute a more progressive politics that would actively seek to grow the commonwealth available to commoners. I refer to this political project as "subversive commoning".

In this final section, I outline how a commons praxis might overcome these two difficulties. First, I discuss the problem of organisational form by building upon lessons from recent critical scholarship. Second, I discuss 'subversive commoning', which would address the need for a progressive political project for moving the commons forward. In each section, I will be narrowing the focus to the digital commons, although these proposals may have broader appeal to a variety of commons-based movements.

\subsection{Political Organisation from Below: Decentralisation, Autonomy, and Boundary Commoning}

There is a contradiction that exists today for organising political resistance. On the one hand, the spread of digital technologies has assisted diverse and fragmented publics in linking with others to form networked communities of interest. Such communities, like those involved in free software projects, rely on inputs from a distributed community of contributors who can collaboratively produce goods, services, or create new meanings for cultural texts. On the other hand, these communities continue to operate from within existing institutions, which operate according to liberaldemocratic logics. These networked publics have challenged previously held assumptions. As just two examples of this, consider the challenge to assumptions about ownership (i.e., the rise of copyleft licenses to challenge traditional copyright protection), and to production bounded to a specific nation-state and its regulatory policies (i.e., globalised commodity supply chains and the question of whether a product is 'Made in the USA' or any other single country).

This raises the question of what organisational form political resistance should take from within this context. On the one hand, we want to preserve the relative autonomy of local communities to organise in ways that make the most sense for the community. On the other hand, we are confronted with existing institutions that require the coordination of diverse movements to effect change within those institutions. As it concerns the digital commons, Dulong de Rosnay and Musiani (2016) have developed a typology of centralised versus decentralised peer production that is instructive here. The typology can be seen below in Table 4. The goal for the digital commons would be to move increasingly toward the decentralised models presented in the table. Doing so would allow local communities to respond to unique needs and simultaneously preserve the highest degree of autonomy for the community. 


\begin{tabular}{|c|c|c|c|c|c|}
\hline & Ownership & Technology & Governance & Rights & Value \\
\hline Centralised & $\begin{array}{l}\text { Company } \\
\text { Major Plat- } \\
\text { forms }\end{array}$ & $\begin{array}{l}\text { Central server } \\
\text { controlled by } \\
\text { platform owner }\end{array}$ & $\begin{array}{l}\text { Top-down } \\
\text { decision- } \\
\text { making by } \\
\text { platform } \\
\text { owner }\end{array}$ & $\begin{array}{l}\text { Exclusive } \\
\text { rights as- } \\
\text { signed to } \\
\text { platform } \\
\text { owner }\end{array}$ & $\begin{array}{l}\text { Concentrated } \\
\text { in hands of } \\
\text { platform } \\
\text { owner }\end{array}$ \\
\hline Decentralised & $\begin{array}{l}\text { Cooperative } \\
\text { non-profit } \\
\text { Informal un- } \\
\text { structured } \\
\text { collaboration }\end{array}$ & $\begin{array}{l}\text { Several user- } \\
\text { controlled com- } \\
\text { puters/nodes } \\
\text { linked in a peer- } \\
\text { to-peer network }\end{array}$ & $\begin{array}{l}\text { Participative } \\
\text { democracy } \\
\text { Autonomy of } \\
\text { peers }\end{array}$ & $\begin{array}{l}\text { Terms of } \\
\text { contribution } \\
\text { leaving } \\
\text { some rights } \\
\text { to contribu- } \\
\text { tors }\end{array}$ & $\begin{array}{l}\text { Redistributed } \\
\text { within com- } \\
\text { munity and/or } \\
\text { society at } \\
\text { large }\end{array}$ \\
\hline
\end{tabular}

Table 4. Centralised Versus Decentralised Peer Production (Dulong de Rosnay and Musiani 2016, 196)

However, these diverse and distributed communities would still need to be linked through common interests to mount a significant challenge to existing institutions. This is where De Angelis's use of 'boundary commoning' becomes useful. As discussed earlier, boundary commoning allows specific communities to retain their autonomy, while also linking with other organisations through common interests. While similar organisational structures have been used in the past - namely, the federated approach taken by Indymedia (see Pickard 2006) - the commons offer a framework that is widely applicable and capable of linking diverse movements under a common framework. Importantly, however, such a movement ought to be based on an antagonistic understanding of the commons' relation to capitalism. The specifics of this political project are outlined in the following section.

\subsection{Subversive Commoning: Toward a Progressive Politics for Commons Praxis}

As discussed earlier in this article, the unique characteristics of the digital commons - low rivalry and low excludability - make it possible for the products of peer production to be appropriated by the state and capital. Similar arguments have been made within critical scholarship on the commons, more generally. Specifically, scholars have drawn on the concept of "enclosure" to refer to the ways that common resources are transferred to private owners (Marx 1976; Harvey 2009; Linebaugh 2014). The term "enclosure" is useful for conceptualising the capture of common resources for capital accumulation, but it does not describe the use of digital commons fully, as such resources do not become entirely closed off from the community that produced the resource. Rather, digital commons become dialectically situated between both capital and the commonwealth. As such, commons-based movements will actively need to work to subvert capital logics by positioning their activities in an antagonistic relationship to capital.

By seeking reformist agendas from within existing institutions, such movements risk remaining small-scale, fragmented, and only capable of temporary subsistence rather than formulating a coordinated alternative to prevailing logics. Therefore, commons-based movements need to move beyond a politics of provision (based on the granting of individual rights, open access, etc.). Such a politics would not only provide rights of access to community members, but the sources of their commonwealth would also continue to be susceptible to capital and state appropriation. To be sure, the inroads made by movements informed by liberal-democratic political econ- 
omy have led to the widespread adoption of particular commons-based resources (see especially Linux and the technologies of free and open sources software). But insofar as these resources are available to capital, they only exacerbate or accelerate the inequities involved in circuits of capital accumulation.

One of the most well-developed proposals for reforming existing institutions to bring about a commons-based society comes from the P2P Foundation (2017) and its Commons Transition Plan. The plan outlines policy prescriptions for moving away from the state/market duopoly toward a "commons-centric society in which a postcapitalist market and state are at the service of citizens as commoners" (P2P Foundation, 2017, 13). As I have outlined throughout this paper, however, the dilemma of how to ensure that the value created by commons-based movements remains within the commons persists. Bauwens and Niaros (2017) explore this dilemma through an analysis of value within the commons economy. The authors argue that economic theory is experiencing a "value crisis" in light of the emergent practices of commonsbased communities. They argue that whereas value within capitalism is extractive, a shift to a generative value model would enrich the communities and resources directly involved in production. The open cooperative and platform cooperative (Scholz 2014) are organisational forms that have been developed as a means for directly enriching those involved in production. However, the specific tactics used by open cooperatives to ensure that the value created by their contributors stays within the commons varies. Bauwens and Niaros (2017) provide case studies that illustrate these differences. Most important for the purpose of my argument, however, is the question of how value can be actively re-appropriated from capital and placed into the commons value circuit.

My argument is that we need a form of 'subversive commoning', which would actively seek to incorporate resources into commons value circuits. Just as capital operates according to a logic of capital accumulation by dispossession (Harvey 2009), so too can commons-based movements reverse this logic to establish a site of social struggle. This could be framed as commons pooling by capital dispossession, although there are a couple of caveats to such an expression. First, I use the term 'pooling' here to signal an opposition to the private accumulation of capital. However, commons-based movements need to find ways of actively growing their commoning capacity over time. Doing so could accelerate the pace of the social revolution described by Marx, as well as more recently by De Angelis. Second, 'dispossession' is not necessarily an entirely accurate term when applied to the digital commons. Rather, digital resources could be appropriated by commons-based movements to serve their own needs.

Bauwens and Niaros use the term "reverse co-optation" to describe the ways in which commons-based movements can "use capital from the capitalist or state system, and subsume capital to the new logic" of the commons $(2017,3)$. The example given by the authors is the open cooperative, Enspiral, which uses a policy of 'capped returns' to protect its operations from the perpetual returns that investors often seek when investing in a company. In essence, shares in a new company are offered to investors along with an option for the company to repurchase those shares at an agreed upon price in the future. The idea is that the interests of the investor and the cooperative become aligned; both have an interest in seeing the cooperative succeed. The investor will be guaranteed some return on the initial investment, and the cooperative will have full control of its finances. In the case of Enspiral, once the capped return contract has been fulfilled, all resources are then given to the com- 
mons. In this sense, Enspiral provides an example of how an open cooperative can actively grow common-pool resources.

While Enspiral provides one example of how the commons can grow, my idea for 'subversive commoning' would include many other examples. At a general level, we can think of movements to reclaim farming, housing, forests, and other natural resources by either occupying abandoned space or actively resisting the enclosure of ancestral lands. These activities are directly subversive to capital because they actively re-appropriate sites of capitalist production into cooperative or commons-based movements. But we also have examples from within the digital commons. For example, organisations like RiseUp or Saravá provide "online communication tools for people and groups working on liberatory social change" (RiseUp 2017). In addition, FemHack provides a space for feminist and queer hackers to "hack patriarchy, capitalism, and other systems of oppression", and the group actively works to encode non-hierarchical values into their technologies and networked infrastructures (foufem 2016). These organisations, which have been effectively built from nothing, have the subversion of the logic of capital at the core of their foundational principles. Apart from within organisations that provide digital infrastructures, tools, and services to assist in the project of bringing about social change, subversive commoning can also be seen in attempts to release knowledge and information that has been closed off from public access. Aaron Schwartz's downloading and release of academic articles held in the JSTOR database provides an example of commoning knowledge that was enclosed by the capitalist logic of publishing companies. What all these examples have in common is the subversive nature of their activities in attempting to undermine prevailing capitalist logics that either enclose knowledge and information behind paywalls or institute hierarchical systems of management, surveillance, and control over information resources. Any attempt to subvert these logics could provide an example of subversive commoning. Subversive commoning responds by appropriating these resources and re-encoding them within the logics of commons value circuits as well as within subjectivities that emphasise care, trust, mutual aid, and conviviality, while recognising the social value in social production.

\section{Conclusion}

Both the products and processes involved in FLOSS and the digital commons continue to confront the state and capital, both of which can have either a direct or indirect influence on their community resources and relations. Critical scholars, however, have argued for ways of moving the commons forward, even though the systems and subjectivities of commons-based movements clash or intersect with broader circuits of capital accumulation. By exploring the radical potential of commons-based social movements in this way, I intended to explore the emancipatory potential of the commons to bring about a postcapitalist future.

The argument developed in this article unfolds along two axes. First, I made an analytical argument by building off recent critical scholarship. By drawing examples from the free software movement, I argued that a critical political economy that is grounded in a dialectical understanding of the contradictions inherent in the dichotomy of capital and the commons offers a clear framework for understanding the extent to which the digital commons can truly become emancipated from broader structures of capital accumulation. Second, I offered some provisional arguments about a commons praxis. This argument proceeded along two lines: first was the need to develop an organisational form that preserves the autonomy of local communities while still mounting a coordinated challenge to existing institutions; and second was the devel- 
opment of progressive political projects for transcending the contradictions that exist between capital and the commons, while providing some possible directions forward. I argued that boundary commoning provides a useful framework for understanding organisational form, while subversive commoning provides a way for framing the antagonistic position of commons-based movements. By incorporating these two strategies, the project for bringing about a commons-based society can proceed, but it will still proceed as a more general process of social struggle.

\section{References}

Bauwens, Michel. 2005. The Political Economy of Peer Production. CTheory. Accessed 28 July 2017. http://www.ctheory.net/articles.aspx?id=499

Bauwens, Michel and Vasilis Kostakis. 2014. From the Communism of Capital to Capital for the Commons: Toward an Open Co-operativism. tripleC: Communication, Capitalism \& Critique. Open Access Journal for a Global Sustainable Information Society. 12 (1): 356361.

Bauwens, Michel and Vasilis Niaros. 2017. Value in the Commons Economy: Developments in Open and Contributory Value Accounting. Co-published by Heinrich-Böll Foundation and P2P Foundation. Accessed 18 January 2018.

https://www.boell.de/en/2017/02/01/value-commons-economy-developments-open-andcontributory-value-accounting

Benkler, Yochai. 2006. The Wealth of Networks: How Social Production Transforms Markets and Freedom. New Haven: Yale University Press.

Birkinbine, Benjamin. 2017. From the Commons to Capital: Red Hat, Inc. and the Business of Free Software. Journal of Peer Production 10. Accessed 28 July 2017.

http://peerproduction.net/issues/issue-10-peer-production-and-work/from-the-commonsto-capital/

Bollier, David and Silke Helfrich. 2012. The Wealth of the Commons: A World Beyond Market and State. Amherst: Levellers Press.

Broumas, Antonios. 2017. Social Democratic and Critical Theories of the Intellectual Commons: A Critical Analysis. tripleC: Communication, Capitalism \& Critique. Open Access Journal for a Global Sustainable Information Society. 15 (1): 100-126.

Corbet, Jonathan and Greg Kroah-Hartman. 2016. Linux Kernel Development: How Fast is it Going, Who is Doing it, What they are Doing and Who is Sponsoring the Work. $25^{\text {th }}$ Anniversary Edition. The Linux Foundation.

Dalla Costa, Mariarosa and Selma James. 1975. The Power of Women and the Subversion of the Community. Bristol: Falling Wall Press.

De Angelis, Massimo. 2017. Omnia Sunt Communia. London: Zed Books.

Dulong de Rosnay, Melanie and Francesca Musiani. 2016. Toward a (De)CentralizationBased Typology of Peer Production. tripleC: Communication, Capitalism \& Critique. Open Access Journal for a Global Sustainable Information Society. 14 (1): 189-207.

foufem. 2016. Fem Hack! [website] Accessed 28 July 2017. http://foufem.wiki.orangeseeds.org/

Frischmann, Brett. 2012. Infrastructure: The Social Value of Shared Resources. Oxford: Oxford University Press.

Hardin, Garrett. 1968. The Tragedy of the Commons. Science 162 (3859): 1243-1248.

Hardt, Michael and Antonio Negri. 2011. Commonwealth. Cambridge: Harvard University Press.

Harvey, David. 2009. The 'New' Imperialism: Accumulation by Dispossession. Socialist Register 40: 63-87.

Hess, Charlotte and Elinor Ostrom. 2007. Understanding Knowledge as a Commons: From Theory to Practice. Cambridge: MIT Press. 
Lee, Micah, Glenn Greenwald and Morgan Marquis-Boire. 2015, July 2. Behind the Curtain: A Look at the Inner Workings of NSA's XKEYSCORE. The Intercept. Accessed 28 July 2017. https://theintercept.com/2015/07/02/look-under-hood-xkeyscore/

Lessig, Lawrence. 2005. Free Culture: The Nature and Future of Creativity. New York: Penguin.

Linebaugh, Peter. 2014. Stop, Thief!: The Commons, Enclosures, and Resistance. Oakland: PM Press.

Linebaugh, Peter. 2008. The Magna Carta Manifesto. Berkeley: University of California Press.

Locher, Fabien. 2016. Third World Pastures: The Historical Roots of the Commons Paradigm, 1965-1990. Quaderni Storici 51 (1): 303-333.

Luhmann, Niklas. 1995. Social Systems. Stanford: Stanford University Press.

Machlup, Fritz. 1962. The Production and Distribution of Knowledge in the United States. Princeton: Princeton University Press.

Marx, Karl. 1976. Capital: A Critique of Political Economy, Volume 1. New York: Penguin.

Maturana, Humberto and Francisco Varela. 1998. The Tree of Knowledge: The Biological Roots of Human Understanding. Boston: Shambhala.

Moody, Glyn. 2001. Rebel Code: The Inside Story of Linux and the Open Source Revolution. Cambridge: Perseus Press.

Ostrom, Elinor. 1990. Governing the Commons: The Evolution of Institutions for Collective Action. Cambridge: Cambridge University Press.

P2P Foundation. 2017. Commons Transition. Accessed 17 July 2017. http://commonstransition.org/

Pickard, Victor. 2006. United Yet Autonomous: Indymedia and the Struggle to Sustain a Radical Democratic Network. Media, Culture \& Society, 28 (3): 315-336.

Riseup. 2017. Riseup [website]. Accessed 29 July 2017. https://riseup.net/

Scholz, Trebor. 2014. Platform Cooperativism vs. the Sharing Economy. Medium. Accessed 18 January 2018. https://medium.com/@trebors/platform-cooperativism-vs-the-sharingeconomy-2ea737f1b5ad

Tapscott, Don and Anthony Williams. 2006. Wikinomics: How Mass Collaboration Changes Everything. New York: Portfolio.

Thompson, Edward Palmer. 1993. Customs in Common: Studies in Traditional Popular Culture. New York: The New Press.

Treanor, Paul. 2005. Neoliberalism: Origins, Theory, Definition. Accessed 28 July 2017. http://web.inter.nl.net/users/Paul.Treanor/neoliberalism.html

Von Hippel, Eric. 2005. Democratizing Innovation. Cambridge: MIT Press.

Weber, Steven. 2004. The Success of Open Source. Cambridge: Harvard University Press.

\section{About the Author}

Benjamin J Birkinbine

Benjamin J Birkinbine is an International Research Fellow at the Westminster Institute for Advanced Studies at the University of Westminster and an Assistant Professor of Media Studies at the Reynolds School of Journalism and Center for Advanced Media Studies at the University of Nevada, Reno. His research focuses on the political economy of communication, with a specific focus on free and open source software and the digital commons. He is the co-editor of Global Media Giants (Routledge, 2017), and his research has been published in the International Journal of Communication, The Political Economy of Communication, and the Journal of Peer Production. 